\title{
Sib risk and the dizygotic twin concordance rate for multiple sclerosis
}

\author{
WILLIAM H JAMES \\ From the MRC Mammalian Development Unit, Wolfson House (University College London), 4 Stephenson \\ Way, London NW1 $2 H E$
}

SUMMARY Data have been reviewed on sib risk and the dizygotic twin concordance rate in multiple sclerosis. Even when rigorous criteria are applied, the dizygotic twin concordance rate for multiple sclerosis is apparently higher (perhaps 10 times higher) than could be explained by the sib risk. In contrast, twins with Parkinson's disease have low concordance rates even when ascertainment is by informal methods. It is concluded that such methods of ascertainment are not as biased as has been suggested, and that the high concordance rates reported for multiple sclerosis are a characteristic of the disease rather than an artifact of the ascertainment. Three hypotheses are considered which might, in principle, explain this high dizygotic twin concordance rate in multiple sclerosis:

1 One is certainly false, viz, that it is due to an excessive liability of dizygotic twins to the disease.

2 It is possible that a pathogen occurs in early infancy or in pregnancy itself.

3 It seems more likely that the high concordance rate may be explained in terms of age related events or sequences of events. (If such events were pathogenic for one member of a sibship, they would be pathogenic for another only if it were a co-twin.)

I suggested ${ }^{1}$ that the concordance rate for multiple sclerosis (MS) in dizygotic (DZ) twins may be higher than can be accounted for by the sib risk; and a similar suggestion has since been made by other workers. ${ }^{2}$ However, as the suggestion has met with some scepticism, ${ }^{3}$ I want to review the evidence on both sorts of data involved in that contrast. These data on MS will also be compared with analogous data on Parkinson's disease.

\section{A review of data on sib risk and $D Z$ twin concordance for MS}

Tables 1 and 2 summarise all the relevant empirical data on MS known to me.

If concordance in twins were due merely to the known raised sib risk, then $r=2 c$, where $r$ is the sib risk and $\mathrm{c}$ the concordance rate (proportion concordant among affected twin pairs).

It is perfectly clear that if these data were accepted at face value, then the concordance rate is far higher than can be accounted for by the sib risk. The sib risk seems to be of the order of $1 \%$, and the concordance rate of the order of $10 \%$, a value which prima facie is 20 times too high for the null hypothesis.
Accordingly, the data must be scrutinised. It is a matter of judgment to decide to what extent they may be accepted. To facilitate this judgment, let us consider the possible sources of bias. Interest here attaches to biases occasioning high estimates of concordance rates or low estimates of sib risks. A catalogue of the various sorts of bias is now offered with comments on their relevance to this particular interest.

\section{THE BIASES}

1 Multiple sclerosis is a difficult disease to diagnose; in many cases firm diagnosis is not made until necropsy. The result of this uncertainty is that living patients are usually classified as 'probable' or 'possible'. This leads to a range of categories (rather than 'concordant' or 'discordant') into which pairs of sibs may be classified. However none of these considerations seems to suggest that estimates of concordance rates are more biased than, or biased in a different direction from, those of sib risks.

2 Sib risks and twin concordance rates are both (roughly equally) underestimated because a sib or twin, who is unaffected at the time of survey, may later develop the disease. It is true that if the average 
Table 1 Numbers of DZ twin pairs concordant and discordant for $M S$ reported by various authors

\begin{tabular}{|c|c|c|}
\hline Author & Concordant pairs & Discordant pairs \\
\hline Heltberg \& Holm ${ }^{3}$ & 1 & 27 \\
\hline Bobowick et al ${ }^{10}$ & 0 & 4 \\
\hline Currier \& Eldridge ${ }^{14}$ & 3 & 26 \\
\hline Mackay \& Myrianthopoulos ${ }^{4}$ & 6 & 23 \\
\hline Schapira et al ${ }^{11}$ & 0 & 2 \\
\hline Thums ${ }^{15}$ & $1 ?$ & 29 \\
\hline $\mathrm{Koch}^{16}$ & $1 ?$ & 5 \\
\hline Bammer et $a l^{12}$ & $1+1 ?$ & 5 \\
\hline Cendrowski ${ }^{13}$ & 0 & 3 \\
\hline Schwermann ${ }^{17}$ & 1 & 7 \\
\hline Williams et $a^{18}$ & 2 & 10 \\
\hline
\end{tabular}

See notes on p. 42

Table 2 Numbers of cases of MS in sibs of index cases

\begin{tabular}{|c|c|c|c|}
\hline \multirow[b]{2}{*}{ Place } & \multirow[b]{2}{*}{ Author } & \multicolumn{2}{|l|}{ Sibs } \\
\hline & & Total & Affected \\
\hline Switzerland & Curtius \& Speer ${ }^{20}$ & 444 & 4 \\
\hline England \& Wales & Pratt et $a l^{20}$ & 538 & 6 \\
\hline Sweden & Muller ${ }^{21}$ & 2268 & 22 \\
\hline Northern Ireland & Allison \& Millar" & 2939 & 34 \\
\hline Northern Scotland & Sutherland ${ }^{2 s}$ & 547 & 7 \\
\hline Northumberland \& Durham & Schapira et al ${ }^{11}$ & 2151 & 25 \\
\hline Vestfold, Norway & Oftedal ${ }^{24}$ & 554 & 6 \\
\hline Møre og Romsdal, Norway & Presthus ${ }^{25}$ & 335 & 4 \\
\hline British Columbia & Sadovnick \& MacLeod ${ }^{26}$ & 1179 & 33 \\
\hline United States & Mackay \& Myrianthopoulos & $\begin{array}{r}207 \\
11162\end{array}$ & $\begin{array}{r}8 \\
149\end{array}$ \\
\hline
\end{tabular}

By pooling all these data, one may derive a sib risk of $149 / 11162 \simeq 0.013$. See notes on p. 42

interval between the onsets of MS in non-twin sibs were greater than that relating to concordant twins, then some slight underestimate of sib risk (contrasted with twin concordance rate) would result. But it is not clear that the one interval is greater than the other.

3 Both sib risks and twin concordance rates have probably been underestimated (roughly to the same degree) because familial involvement will naturally suggest another diagnosis (eg, spastic ataxia and paraplegia) rather than MS.

4 It is important that pairs of cases (whether of sibs or twins) should be ascertained within series rather than presented on account of their rarity. If this principle is not adhered to, then it is impossible to make a numerical assessment of this rarity. Of all the sources of bias, this alone seems to be of greater magnitude in regard to twins than to other sibs. The sib risks offered in table 2 may be regarded as unbiased estimates at the time of survey. It is not clear that concordant pairs of sibs are more likely to be reported than discordant pairs. However the twin data presented in table 1 cannot all be regarded as unselected. In particular, the data of Mackay and Myrianthopoulos ${ }^{4}$ were collected as a result of an appeal for twins with one or both affected. So there is a suspicion that concordant pairs would be more likely to be ascertained.

Analysis of the data on DZ twin concordance in MS Using the most rigorous criteria (accepting only the data recommended in Note a to table 1) it will be seen that one probable plus two certain concordant pairs occurred among $44 \mathrm{DZ}$ twin pairs affected by MS. If we accept a sib risk of 0.013 (derived from the data in table 2), then there were $(44 / 2) \times 0.013=0.286$ concordant pairs expected. The Poisson probability of 2 or more events occurring when 0.286 are expected is close to 0.03 : and the probability of 3 or more occurring is less than $0 \cdot 005$. So there can be no reasonable doubt that more DZ pairs are concordant for MS than would be predicted on the basis of sib risk. The magnitude of this risk factor is of the order of $(2+1 ?) / 0 \cdot 286 \simeq 10$. To offer confidence limits for this factor would attribute a spurious precision to it. However, bearing in mind all the data in table 1, and the notes on them, it still seems that 10 is a reasonable estimate of that factor.

\section{A comparison of MS with Parkinson's disease}

It seems worth contrasting this high $\mathrm{DZ}$ twing concordance rate for MS with the comparable figure for Parkinson's disease (PD). Like MS, this is a progressive neurological disorder of unknown cause. Like MS sufferers, PD patients have a much reduced life expectancy. Both diseases have a very variable age at onset, though the mean age at onset of PD is greater than that at onset of MS. Both diseases present difficulties in diagnosis, each being occasionally misdiagnosed in patients with the other disorder. Both diseases show unequivocal signs at necropsy, but no objective markers are available whereby diagnosis can reliably be made during life. Of interest in the present context is the fact that PD, like MS, has been thought to have some (perhaps weak) genetic determinants. Family histories have been reported to contain PD patients in up to four generations. ${ }^{\mathrm{J}}$

The purpose of the present excursus may now be apparent. We are interested in concordance rates in PD twins ascertained with the same sorts of bias as those characterising the ascertainment of some of the MS twins reviewed above. A recent study offers such data. ${ }^{6}$ I quote the description of the ascertainment: "Twin pairs in whom one or both were said to have PD were sought through adult twin registries in the United States and through notices in medical journals, notices in newsletters of voluntary PD organisations, announcements at neurology meetings, and informal inquiries among professional 
colleagues". The results were as follows: among 43 monozygotic (MZ) and $19 \mathrm{DZ}$ pairs in which an index case had definite $P D$, only one $M Z$ pàir was definitely concordant. When pairs with questionable clinical features were included, 4 out of $48 \mathrm{MZ}$ and 1 of $19 \mathrm{DZ}$ pairs were concordant. The authors conclude that: "the concordance rate for MZ twins is low and likely to remain so during extended follow up. The frequency of $\mathrm{PD}$ in the $\mathrm{MZ}$ co-twins of affected index cases is probably identical to the frequency to be expected in a group of unrelated controls matched for age and sex".

I suggest that this conclusion (based on the ascertainment described above) indicates that ascertainment by such relatively informal methods does not in itself greatly affect the probability of inclusion of concordant pairs. (The alternative inference is that PD in one member of a twin pair protects the other member from the disease. This view is supported by the fact that among sporadic reports of PD twins, discordant pairs outnumber concordant pairs by 5 to $1 .^{5-9}$

Accordingly, I suggest that the high concordance rates for MS, reported in both $M Z$ and $D Z$ twin pairs, are not wholly artifacts of admittedly imperfect methods of ascertainment but are real features of the disease.

What can be the cause of this? Three hypotheses will be discussed.

\section{HYPOTHESIS 1}

\section{That $D Z$ twins are particularly prone to $M S$}

If $\mathrm{DZ}$ twins were particularly prone to MS, then DZ twin concordance rates would be expected to be high compared with sib risk. However the facts do not suggest that $\mathrm{DZ}$ twins are at additional risk. The only data I have on the incidence of twins in samples of MS patients point decisively in the opposite direction. Cendrowski ${ }^{13}$, Shapira et al, ${ }^{11}$ and Allison \& Millar ${ }^{22}$ together report nine discordant twin pairs among 1635 MS patients. At the time of birth of these patients about 1 maternity in 80 was of twins, so about 1 birth in $\mathbf{4 0}$ was of a twin. Perinatal mortality and infant mortality are substantially greater in twins, but after the first year the mortality differential seems largely to disappear. So, using the data cited by Bulmer, ${ }^{30}$ one would expect about 1 twin in 46 adults. Whence one might have expected about 35 instead of the nine twin pairs actually observed in the pooled data cited above. Confirmatory evidence on this point is provided by the data of Bobowick et al, ${ }^{10}$ who estimated that among their sample of 16000 adult male twins aged 53-63, the proportion suffering from MS was about half the proportion estimated on population age specific rates. (In parenthesis it might be remarked that the deficit of MS in twins may be explained by the facts that (a) birth order is positively associated with (dizygotic) twinning, and (b) birth order seems to be negatively associated with MS. ${ }^{31}$ ) In conclusion, it is clear that the high concordance rate in DZ twins is not accounted for by an excess of MS in DZ twins.

\section{HYPOTHESIS 2}

That a pathogen occurs in pregnancy or infancy So it seems that DZ twins must somehow experience a greater similarity of environmental exposure than do other pairs of sibs. But how? Several kinds of hypothesis may be formulated. Twins obviously spend more time in one another's company in infancy (and later) than do other pairs of sibs. This could scarcely account for a 10 -fold risk ratio unless a pathogen occurs in infancy or in pregnancy itself. As far as I know, little attention has been paid to this possibility. It might be worth looking at the in utero experience of patients.

Did the mothers suffer from any dietary deficiency or infection during pregnancy? A point against this hypothesis is that MS seems not to be associated with lower social class. ${ }^{32}$ Moreover, migration studies have made it fairly clear that a pathogen occurs during childhood, ${ }^{33}$ though this does not rule out that it (or another pathogen) should sometimes occur earlier.

\section{HYPOTHESIS 3}

\section{That MS follows a sequence of events}

Suppose the pathogen consists of a sequence of events, each of which must occur during a limited age range (eg, event $A$ at age 2 and event $B$ at age 4). If this were so, and if events $A$ and $B$ occurred in a household at times that were pathogenic for one sib, they might not be so for another unless it was a twin. The point may be illustrated as follows. Suppose (as has been proposed) that MS is dependent on an infection which is harmless in early childhood but pathogenic if it first occurs later in life. (Such a suggestion is supported by the indications that MS is more likely to occur in first born children. ${ }^{31}$ ). In such circumstances, one would expect a high concordance rate in $\mathrm{DZ}$ twins compared with sib risk.

The hypothesis may be elaborated as follows. It seems to be well established that (in some samples) measles antibody titres are higher in MS patients than in their controls. ${ }^{34}$ Moreover, the geographical distribution of measles is unlike that of MS; hence the inference that if measles does play some part, then a cofactor is also responsible. Let us, for example, suppose that event $B$ is a measles infection. (This is consistent with the suggestion that MS patients have measles later than controls. ${ }^{35}{ }^{36}$ ) What then about the identity of event $\mathbf{A}$ ? We need some agent which 
increases in prevalence with latitude. One might suggest the common cold, influenza or pneumonia. (These are merely suggested as examples; readers may supply their own.) Of these, pneumonia would be the most attractive to test because $(a)$ it is rarer and would be better recorded, and $(b)$ any hypothesis invoking a very common disease carries the additional burden of explaining why it is not always pathogenic.

I am grateful to Mrs June Rathbone of Galton Laboratory for help with the translation.

\section{Notes to Table 1}

These notes deal with the adequacy of sampling of twin pairs affected by MS.

(a) The data of Heltberg \& $\mathrm{Holm}^{3}$, Bobowick et $a l^{10}$, Schapira et a ${ }^{11}$, Bammer et $a l^{12}$ and Cendrowski ${ }^{13}$ may be accepted as adequately ascertained within series.

(b) As noted above, the data of Mackay and Myrianthopoulos ${ }^{4}$ are clearly suspect; and, to a lesser extent, so are those of Currier and Eldridge ${ }^{14}$. (Some cases are common to these two sets of data.) The data of Currier and Eldridge were collected via a notice in the patient bulletin of the Multiple Sclerosis Society. Probably less bias attaches to such a proceeding than to a public appeal because patients, administrative workers, and ancillary workers are all likely to be responsive to the research imperative in such a milieu-so presumably almost all twins known to the Society would get ascertained. It seems, however, that any rigorous assessment of the data would dictate exclusion of this material.

(c) It is difficult to know how to deal with the data of Thums ${ }^{15}$. He regarded his single concordant pair as doubtful. It would seem unduly cautious to exclude this pair but to include the discordant pairs; but it might be incautious to include both. So all his material will be excluded here.

(d) The data of $\mathrm{Koch}^{16}$ are a collection of single cases published separately by different authors. They were not ascertained in series so they must be excluded here.

(e) The series of Schwermann ${ }^{17}$ was ascertained from the records of a neurological clinic in Munster. If a patient was identified in these records as a twin, then he/she was included. It is not clear if the recording of the twinship was made as a result of a question which was routinely asked of all patients. If it was, then the ascertainment seems to have been unbiased. If, on the other hand, it depended on the patient volunteering the information, then biased ascertainment may have resulted as a consequence of the fact that a patient would be more likely to volunteer information about a concordant than a discordant co-twin. In face of this uncertainty, these data will be ignored.

(f) The cases of Williams et $a^{18}$ were ascertained via a notice in the MS Messenger, the newsletter of the MS Society of the USA. Only like-sexed pairs were accepted. This method of ascertainment is like that of
Currier \& Eldridge (and one may wonder whether the two series contain pairs in common). So these data cannot be regarded as completely representative.

\section{Notes to Table 2}

1 Where some discretion may be applied to the figures to be accepted, I have preferred to risk overestimating (rather than underestimating) the sib risk in order that the contrast with twin concordance rates may be conservative.

2 The data of Hyllested ${ }^{27}$ have been omitted because Acheson ${ }^{28}$ suggested that they underestimated the sib risk.

3 Muller $^{21}$ noted that in the data of Curtius \& Speer $^{19}$ the diagnosis was not conclusive in any of the four affected sibs: he noted that in two, the diagnosis was 'even extremely questionable'.

4 The data of Pratt et $\boldsymbol{l}^{\mathbf{2 0}}$ contain an affected sib who was dead by the time of the survey.

5 Some uncertainty relates to the data of Oftedal ${ }^{24}$ and of Presthus. ${ }^{25}$ These authors both seem to suggest that ascertainment was practically complete. But their estimations of sib risk may be appropriate instead to single ascertainment (thus halving the estimate of sib risk). Their estimates were accepted by Berry, ${ }^{29}$ but they $\vec{\Phi}$ have been doubled here in order, as argued above, to $\frac{\text { ? }}{\mathrm{D}}$ 윽 keep errors conservative. Numerically these were the twoำ smallest studies, so the point is not of practical importance.

6 The cases of Mackay \& Myrianthopoulos ${ }^{4}$ were ascertained by an affected twin. These authors found nine definite and five possible cases among the 236 sibs of affected twins. However among these 236 sibs, Mackay \& Myrianthopoulos included the co-twins of DZ twin propositi. This clearly is an inappropriate method of estimation of sib risk if it is suspected that the DZ twin concordance rate may be high. So the 29 co-twins (including six affected) of DZ twin propositi have been subtracted. This leaves eight definite and possible cases among the 207 non-twin sibs of twin propositi. There are several reasons for expecting this proportion to be higher than other estimates of sib risk:

(a) Mackay \& Myrianthopoulos make it clear that these sibships had been followed for an unusually long time, thus allowing the sibs more time to have developed the disease.

(b) Twinning (or at any rate $\mathrm{DZ}$ twinning) is associated with positive maternal age and parity effects. ${ }^{30}$ So the twin propositi would be expected on average to occur later in their sibships than would non-twin propositi. Ipso facto the sibs of twin propositi would occur earlier. This constitutes an additional reason for supposing that those sibs had an unusually long time to develop the disease.

(c) Lastly I have reviewed the data and suggested that within sibships early born members are more likely to develop MS than later born members (results to the contrary all being based on invalid tests ${ }^{31}$ ). This being so (and bearing in mind, as argued above, that 
the sibs at risk are in this case likely to be early born), one would expect an unusually high proportion of them to be affected.

\section{References}

${ }^{1}$ James WH. Concordance in twins and recurrence in sibships of multiple sclerosis. Lancet 1982; i: 690 .

${ }^{2}$ Spielman RS, Nathanson $\mathrm{N}$. The genetics of susceptibility to multiple sclerosis. Epidemiol Rev 1982; 4: 45-65.

${ }^{3}$ Heltberg A, Holm NV. Concordance in twins and recurrence in sibships in multiple sclerosis. Lancet 1982; i: 1068 .

${ }^{4}$ Mackay RP, Myrianthopoulos NC. Multiple sclerosis in twins and their relatives. Arch Neurol 1966; 15: 449-62.

${ }^{5}$ Mjones H. Paralysis agitans: a clinical and genetic study Acta Psychiat Scand (Suppl) 1949; 54: 1-195.

${ }^{6}$ Ward CD, Duvoisin RC, Ince SE, Nutt JD, Eldridge R, Calne CB. Parkinson's disease in 65 pairs of twins and in a set of quadruplets. Neurology (Cleveland) 1983; 33: 815-24.

${ }^{7}$ Gudmundsson KR. A clinical survey of parkinsonism in Iceland. Acta Neurol Scand (Suppl) 1967; 33: 9-61.

${ }^{8}$ Kissel P, André JM. Maladie de Parkinson et anosmie chez deux jumelles monozygotiques. J Genet Hum 1976; 24: 113-7.

${ }^{9}$ Pembrey ME. Discordant identical twins. II. Parkinsonism. Practitioner 197; 209: 20-3.

${ }^{10}$ Bobowick AR, Kurtzke JF, Brody JA, Hrubek Z, Gillespie M. Twin study of multiple sclerosis: an epidemiologic inquiry. Neurology (NY) 1978; 28: 978-87.

${ }^{11}$ Schapira K, Poskanzer DC, Miller H. Familial and conjugal multiple sclerosis. Brain 1963; 86: 315-32

12 Bammer H, Schaltenbrand $G$, Solcher $H$. Zwillingsuntersuchungen bei multipler Sklerose. Dtsch $Z$ Nervenheilkunde 1960; 181: 261-79.

${ }^{13}$ Cendrowski WS. Multiple sclerosis discordance in three pairs of dizygotic twins. J Med Genet 1968; 5: 266-7.

${ }^{14}$ Currier RD, Eldridge R. Possible risk factors in multiple sclerosis as found in a national twin study. Arch Neurol 1982; 39: 140-4.

${ }^{15}$ Thums K. Eineiige Zwillinge mit konkordanter multipler Sklerose. Weiner $Z$ Nervenheilkunde 1951; 4: 173-203.

${ }^{16}$ Koch G. Polysklerose. In Humangenetik, Band V/I: P Becker ed. Stuttgart: G. Thieme, 1966: 507-29.

${ }^{17}$ Schwermann M. Beobachtungen an 8 Zwillingspaaren mit Polysklerose. Munster, Dissertation. Cited by Koch.
${ }^{18}$ Williams A, Eldridge R, McFarland H, Houff S, Krebs H, McFarlin D. Multiple sclerosis in twins. Neurology (NY) 1980; 30: 1139-47.

${ }^{19}$ Curtius F, Speer H. Multiple Sklerose und Erbanlage. $Z$ Gesamte Neurol Psychiat 1937; 160: 226-46.

${ }^{20}$ Pratt RTC, Compston ND, McAlpine D. The familial incidence of disseminated sclerosis and its significance. Brain 1951; 74: 191-232.

${ }^{21}$ Müller R. Genetic aspects of multiple sclerosis. $A M A$ Archives of Neurology and Psychiatry, Chicago 1953; 70: $733-40$.

${ }^{22}$ Allison RS, Millar JHD. Prevalence and familial incidence of disseminated sclerosis in Northern Ireland. Ulster Med J 1954; 23 Suppl 2: 29-92.

${ }^{23}$ Sutherland JM. Observations on the prevalence of multiple sclerosis in northern Scotland. Brain 1956; 79: 635-54.

${ }^{24}$ Oftedal S. Multiple sclerosis in Vestfold county. Acta Neurol Scand 1965; 41 Suppl 16: 1-62.

${ }^{25}$ Presthus J. Multiple sclerosis in Møre og Romsdal County, Norway. Acta Neurol Scand 1966; 42 Suppl 19: 12-8.

${ }^{26}$ Sadovnick AD, MacLeod PMJ. The familial nature of multiple sclerosis: empiric recurrence risks for first, second and third degree relatives of patients. Neurology (NY) 1981; 31: 1039-41.

${ }^{27}$ Hyllested K. Disseminated sclerosis in Denmark: prevalence and geographical distribution. Copenhagen: J Jorgensen \& Co, 1956.

${ }^{28}$ Acheson ED. Epidemiology. In Multiple sclerosis: a reappraisal. McAlpine D, Lumsden CE, Acheson ED, eds. Edinburgh \& London: Livingstone, 1965: 1-58.

${ }^{29}$ Berry RJ. Genetical factors in the etiology of multiple sclerosis. Acta Neurol Scand 1969; 45: 459-83.

${ }^{30}$ Bulmer MG. The biology of twinning in man. Oxford: Clarendon Press, 1970: 54.

${ }^{31}$ James WH. Multiple sclerosis and birth order. $J$ Epidemiol Community Health 1984; 38: 21-2.

${ }^{32}$ Miller H, Ridley A, Schapira K. Multiple sclerosis: a note on social incidence. $\mathrm{Br}$ Med J 1960; ii: 343-5.

${ }^{33}$ Alter M, Kahana E, Loewenson R. Migration and risk of multiple sclerosis. Neurology (NY) 1978; 28: 1089-93.

${ }^{34}$ Brody JA, Sever JL, Edgar A, McNew J. Measles antibody titres of multiple sclerosis patients and their siblings. Neurology (NY) 1972; 22: 492-9.

${ }^{35}$ Haile RT, Smith P, Read D, Nassim D, Warlow C, Russell WC. A study of measles virus and canine distemper virus antibodies and of childhood infections in multiple sclerosis patients and controls. J Neurol Sci 1982; 56: 1-10.

${ }^{36}$ Murray TJ. An unusual occurrence of multiple sclerosis in a small rural community. Can J Neurol Sci 1976; 3: $163-6$. 